\title{
Reduction of Pumping Energy Losses in District Heating and Cooling Systems
}

Jacques L. Zakin

Department of Chemical Engineering

and

Richard N. Christensen

Department of Mechanical Engineering

U.S. Capartment of Energy

Washington, D.C. 20585

Grant No. DE-FG01-86CE26565

Final Report 


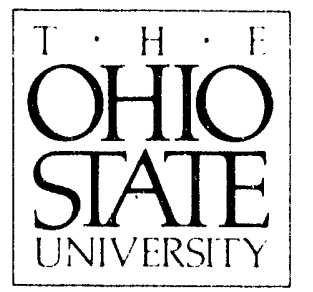

\title{
Reduction of Pumping Energy Losses in District Heating and Cooling Systems
}

\author{
Jacques L. Zakin \\ Department of Chemical Engineering \\ and \\ Richard N. Christensen \\ Department of Mechanical Engineering
}

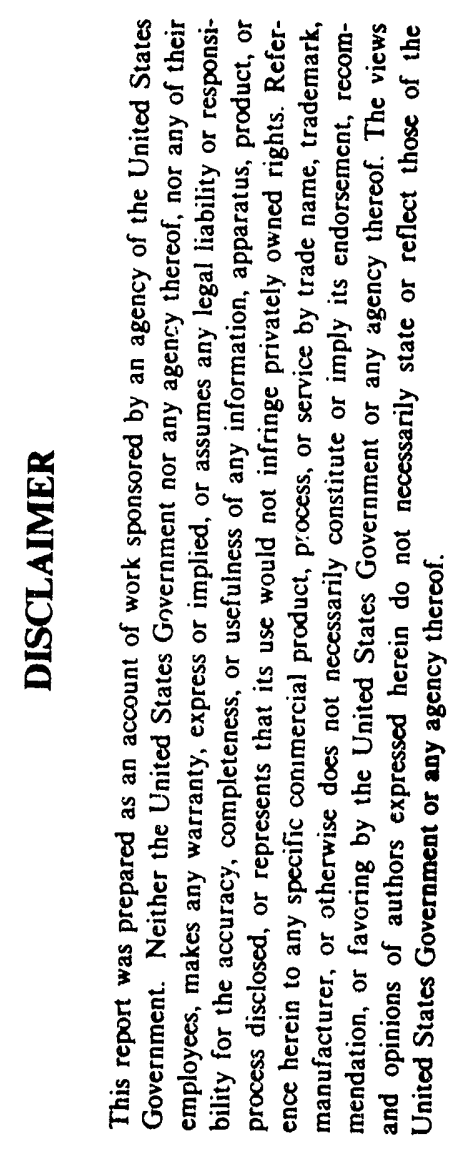

October 1992

U.S. Department of Energy

Washington, D.C. 20585

Grant No. DE-FG01-86CE26565

Final Report

RF Project No. $765571 / 718594$ 


\section{Page}

Introduction

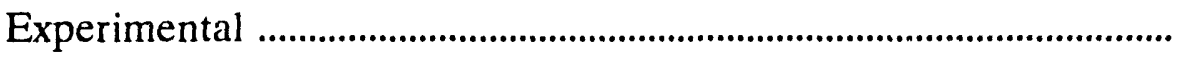

Results and Discussion .............................................................................

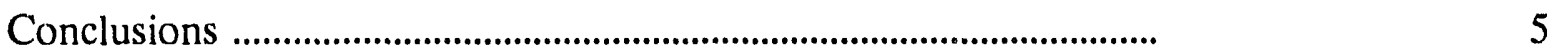

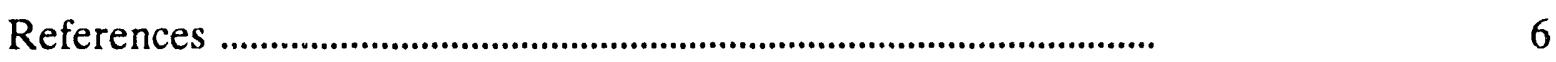

Personnel Involved ..................................................................................

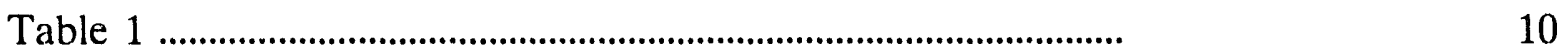

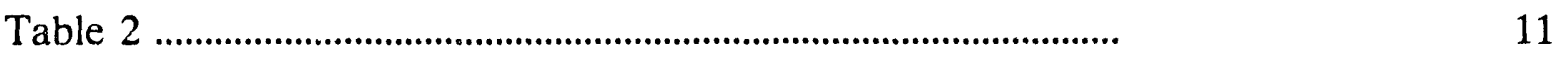

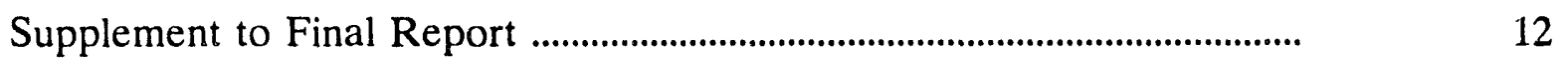

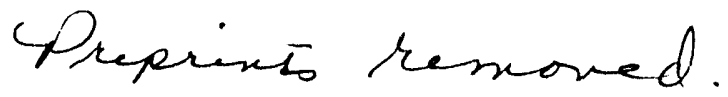




\author{
Final Report \\ Department of Energy Project \\ DE-FG-01-86E-26565
}

Reduction of Pumping Energy Losses in District Heating and Cooling Systems

\title{
Introduction
}

This project was designed to find effective surfactant friction reducing additives for use in district heating systems with temperatures of 50 to $90^{\circ} \mathrm{C}$ and effective additives for district cooling systems with temperatures of 5 to $15^{\circ} \mathrm{C}$. Heat transfer measurements in conventional shell and tube heat exchangers and in plate heat exchangers were also carried out to see how seriously these surfactant drag reducing additives reduce heat transfer coefficients.

\section{Experimental}

The turbulent drag reduction experiments were carried out in two pumping loops described in References 1-4. The low temperature loop was suitable for temperatures ranging from $2^{\circ} \mathrm{C}$ to $100^{\circ} \mathrm{C}$ and the high temperature loop from $30^{\circ} \mathrm{C}$ to $150^{\circ} \mathrm{C}$. Their Reynolds number ranges are 15,000 up to 300,000 . Pressure drop measurements in smooth stainless steel test tubes with diameters of 0.106 and 0.243 inches were made utilizing appropriate entrance and exit kinetic energy loss corrections (4). Turbulent flow test data 
for deionized water lay close to the von Karman equation predictions and repeatability was excellent.

Cationic surfactants with aromatic counter-ions are well-suited for these applications as they have reasonable temperature ranges of effectiveness and, while they do lose their drag reducing effectiveness when exposed to high shear stresses, they regain their drag reducing effectiveness when they enter a lower shear region.

While a large number of commercial quaternary ammoniun salt surfactants and counterions were examined for the high temperature experiments, the experiments focused on eight of them using sodium salicylate as counter-ion. They are listed in Table 1. Surfactants tested for district cooling systems are listed in Table 2.

\section{Results and Discussion}

The experimental results have been reported at national and international meetings (Refs. 1-3, 5, 6). A summary of the results follows. More details are in these papers, a copy of each of which is attached as a supplement.

1. Effect of Alkyl Chain Length on Upper Temperature Limit.

The length of alkyl groups in the quaternary ammonium salts was varied from 10 to 22 carbons using excess salicylate as counter ion (in a ratio of 5 mmoles/12.5 
mmoles). The upper temperature limit increased continuously from $10^{\circ} \mathrm{C}$ with $\mathrm{C}_{\mathrm{i} 0}$ to $120^{\circ} \mathrm{C}$ with $\mathrm{C}_{22}$ (4). Thus, proper selection of the alkyl chain length can provide effective drag reduction up to any desired temperature in this range.

2. Effect of Alkyl Chain Structure on Lower Temperature Limit

The presence of unsaturation in the alky $i$ chain in the quaternary ammonium salt was found to decrease the lower temperature limit for effective drag reduction with no apparent effect on the upper temperature limit (4). Thus, several cationic surfactants containing unsaturated alkyl chains in combination with excess sodium salicylate were effective drag reducers down to $2^{\circ} \mathrm{C}$, the lowest temperature we were able to test (3).

3. Scale-Up of Small Tube Test Results to Larger Tubes.

Most measurements were made in 0.106 and 0.243 -inch diameter tubes. A procedure proposed by Granville (7) for scale-up of polymer drag reducing systems was used for the surfactant drag reducers. Good agreement in scale-up predictions from the 0.106inch tube data with measurements in the 0.243 -inch tube was obtained. Further scale-up to the data which we obtained in Argonne's 6-inch tube also gave reasonable agreement but the assumption of equal wall shear stress could only be approximated as the small tube wall shear stresses were considerably higher than those in the 6-inch tube. We believe this scale-up procedure is satisfactory, but there are several others 
which should also be tested to see if even better agreement can be obtained.

4. Heat Transfer Coefficients for Friction Reducing Surfactant Solutions

Preliminary measurements of heat transfer coefficients at high temperatures (up to $120^{\circ} \mathrm{C}$ ) were made in a tube-in-tube and in a chevron plate heat exchanger (6). Heat transfer coefficients in the tube-in-tube exchanger were reduced as much as $90 \%$ or more at high temperatures. In the plate exchanger, the heat transfer coefficient reduction was smaller but still appreciable (10 to 50\%). Further studies of schemes to reduce the loss in heat transfer or to redesign exchangers to avoid significant reductions in heat transfer are needed.

\section{Corrosion Effects}

Corrosion of metals commonly used in district heating and district cooling systems in contact with surfactant additives was studied (8). Pitting susceptability and corrosion rates of carbon steel, 304 stainless steel, copper, 90\% copper-10\% nickel and $60 \%$ copper-40\% zinc were measured. Exploratory efforts to find suitable corrosion inhibitors were also carried out.

In general, surfactant additives which did not contain chloride ion had no adverse effect on corrosion. The presence of chloride increased the susceptability to pitting of stainless steel in tap water. Al high temperatures, several of the corrosion 
inhibitors tested appeared to be compatible with representative surfactants containing chloride but only hydrazine eliminated pitting susceptability of stainless steel. Hydrazine, while still used in the U.S., is banned in several countries as it is a suspected carcinogen. The use of deionized, deaerated water was at least as effective in reducing corrosion problems as the addition of corrosion inhibitors. Reduction in corrosion problems can also be accomplished by replacing chloride ion present in some surfactant additives with a more benign anion such as acetate.

\section{Conclusions}

1. A number of surfactant drag reducing additives systems suitable for use in district heating systems at temperatures as high as $110^{\circ} \mathrm{C}$ have been demonstrated.

2. A number of surfactant drag reducing additives systems suitable for use in district cooling systems at temperatures as low as $2^{\circ} \mathrm{C}$ were discovered.

3. A procedure for scale-up of measurements of systems in diameters of 0.10 to 0.25 inches to tubes of 6 inches in diameter correlates the available data well.

4. Heat transfer coefficients in drag reduction systems are reduced up to $90 \%$ in tubein-tube exchangers but are reduced only 10 to $50 \%$ in plate exchangers. 
5. Control of corrosion in surfactant systems is no more difficult than in pure water systems. If corrosion inhibitors are to be used, compatibility with the surfactant may be a problem. 


\section{References}

1. L.-C. Chou, R.N. Christensen and J.L. Zakin, "The Use of Cationic Surfactant Additives in District Heating Systems," Proc. Int. District Heating and Cooling Assoc. Conf., Vol. 28, p. 284, Baltimore, June 1987.

2. L.C. Chou, R. N. Christensen and J.L. Zakin, "Effectiveness of Drag Reducing Surfactant Additives in District Heating Systems," Proc. Int. District Heating and Cooling Assoc. Conf., Vol. 29, p. 530, Chautauqua, NY, June 1988.

3. L.-C. Chou, R.N. Christensen, and J.L. Zakin, "The Influence of Chemical Composition of Quaternary Ammonium Salt Cationic Surfactants on Their Drag Reducing Effectiveness," in Drag Reduction in Fluid Flow, R.H. Sellin and R.T. Moses eds., Ellis Horwood Limited Press, Chichester, West Sussex, England, p. 141, 1989.

4. L.C. Chou, "Drag Reducing Cationic Surfactant Solutions for District Heating and Cooling Systems," Ph.D. Dissertation, The Ohio State University, Columbus, in progress.

5. L.-C. Chou, R.N. Christensen and J.L. Zakin, "Drag Reducing Additives for District Cooling Systems," Proc. Int. District Heating and Cooling Assoc. Conf., Vol. 30, p. 352, Virginia Beach, June 1989. 
6. R.N. Christensen and J.L. Zakin, "Drag and Heat Transfer Reduction in Circular Tubes and Plate Fin Heat Exchangers," Proc. Int. District Heating and Cooling Assoc. Conf., Vol. 32, p. 189, San Francisco June 1991.

7. Granville, P.S., "A Method for Predicting Additive Drag Reduction 'rom Small Diameter Pipe Flows," Proc. 3rd Int. Conf. on Drag Reduction, R.H.J. Sellin and R.T. Moses, eds., Univ. of Bristol, U.K., paper C3, 1984.

8. B.C. Smith, B.E. Wilde and J.L. Zakin, "Corrosion Effects of Cationic Surfactant Drag Reducing Additives on Metals Used in District Heating Systems," Proc. Int. District Heating and Cooling Assoc. Conf., Vol. 31, p. 352, Toronto, June 1990.

Personnel Involved

PI - Professor Jacques L. Zakin, Department of Chemical Engineering

Co-PI - Professor Richard N. Christensen, Department of Mechanical Engineering

Dr. Deborah Stutman-Brichey, Visiting Assistant National Science Foundation Woman Professor, Department of Chemical Engineering

Dr. Steve Choi, Argonne National Laboratory

Lu-Chien Chou, Ph.D. candidate, Department of Chemical Engineering 
Bryan C. Smith, Ph.D. candidate, Department of Chemical Engineering A. Singh, M.S. candidate, Department of Mechanical Engineering
Michael Kukla, Design Engineer, Department of Chemical Engineering

Roy A. Renshaw, Instrument Maker, Department of Chemical Engineering Sherry McDonald, Secretary, Department of Chemical Engineering 
Table 1

$\underline{\text { Surfactant Additives and Results }}$

Maximum Wall

Shear Stress

Additives* $^{*}$

Supplier

$\underline{\max ,{ }^{\circ} \mathrm{C}}$

at ${ }^{\top} \max , \mathrm{Pa}$

Arquad 16-50

Akzo Chemical

60

300

Arquad 18-50

Akzo Chemical

$90+$

21.0

Arquad S-50

Akzo Chemical

80-

180

Arquad T-50

Akzo Chemical

70

220

Arquad R-50

Akzo Chemical

90

170

Kemamine Q-2983C

Humko Chem. Div.,

$100+$

150

Witco

Kemamine Q-2803C

Humko Chem. Div.,

110

125

Witco

Ethoquad R12/75

Akzo Chemical

$90+$

200

* Surfactant concentration was 2000 ppm.

In each case $2000 \mathrm{ppm}$ of sodium salicylate was also added. 
Table 2

Low Temperature Drag Reducing Surfactants

Effect of Variation of Cation with Sodium Salicylate as Anion on Critical

Wall Shear Stress $($ Molar Ratio $=1: 1.5 ;$ cation concentration $=5 \mathrm{mmoles} / \mathrm{liter})$

Lowest Temp. for

Significant Drag

Cation

Arquad 12-50

(1606 ppm/1200 ppm)

Arquad S-50

(1726 ppm/1200 ppm)

Ethoquad R/12-75

(2150 ppm/1200 ppm)

Ethoquad 0-12

(2000 ppm/1200 ppm)
10

20

2

95

2

100

Sivear Stress

a. Tmin, $\mathrm{Pa}$

NOTE: Anion is (sodium) salicylate whose concentration is 1200 ppm, giving a surfactant: salicylate molar ratio of $1: 1.5$. 


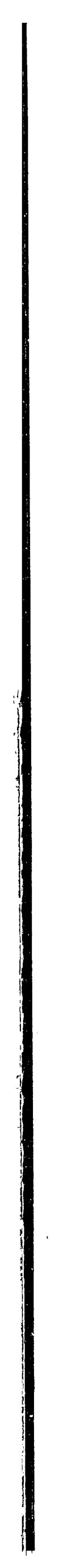

